BULLETIN (New Series) OF THE

AMERICAN MATHEMATICAL SOCIETY

Volume 37, Number 4, Pages 381-405

S 0273-0979(00)00873-9

Article electronically published on June 26, 2000

\title{
PERSPECTIVES ON AMERICAN MATHEMATICS
}

\author{
KAREN HUNGER PARSHALL
}

\begin{abstract}
A research-level community of mathematicians developed in the United States in the closing quarter of the nineteenth century. Since that time, American mathematicians have regularly paused to assess the state of their community and to reflect on its mathematical output. This paper analyzes a series of such reflections-beginning with Simon Newcomb's thoughts on the state of the exact sciences in America in 1874 and culminating with the 1988 commentaries on the "problems of mathematics" discussed at Princeton's bicentennial celebrations in 1946-against a backdrop of broader historical trends.
\end{abstract}

"The prospect of mathematics [in the United States] is about as discouraging as the retrospect" 46, p. 288]. So wrote mathematical astronomer Simon Newcomb in an 1874 essay on the state of the exact sciences in America. He was no more optimistic two years later in his assessment of the abstract sciences at the time of the United States' centennial. "When we inquire into the wealth and power of our scientific organizations, and the extent of their publications - when, in fact, we consider merely the gross quantity of original published research," he wrote, "we see our science in the aspect best fitted to make us contemplate the past with humility and the future with despair" [45] p. 116].

In some sense, Newcomb had every reason to be pessimistic about the development of mathematics and of the mathematical sciences in the United States in the early 1870s. Looking to Europe and universities like those in Berlin and Göttingen, Newcomb saw mathematicians actively engaged both in making original contributions and in imparting that new knowledge directly in their lecture rooms and indirectly through publication. Correlatively, these activities - research, teaching, publication - officially defined the faculty's mission and were encouraged and supported by the government through, in the case of the Prussian universities, the Ministry of Education. Focusing on the situation at home, however, Newcomb found what he termed a "lack of any sufficient incentive to the activity which characterizes the scientific men of other nations, and of any sufficient inducement to make young men of the highest talents engage in scientific research" 46, p. 292]. There were no journals in the United States devoted to mathematical research, and, in fact, up to that time all attempts to sustain such publication outlets had failed almost immediately [46, p. 288], [57, p. 51]. Even if there had been places to publish, there was no shared sense that the advance of knowledge and the communication

Received by the editors January 28, 2000, and in revised form February 21, 2000.

2000 Mathematics Subject Classification. Primary 01A55, 01A60.

An abbreviated version of this paper was presented as an MAA plenary address at the joint meetings of the AMS, MAA, and SIAM in Washington, D.C., on Thursday, 20 January 2000. I would like to thank those who offered comments and suggestions on the content of the talk. 
of that knowledge through publication represented desired ends. America's colleges traditionally emphasized amassing knowledge, not contributing to it, so that, as Newcomb glumly put it, "[h] owever great the knowledge of the subject which may be expected in a professor, he is not for a moment expected to be an original investigator, and the labor of becoming such, so far as his professorial position is concerned, is entirely gratuitous" [46, p. 297]. Finally, even if these deficiencies were corrected, one fundamental problem would still remain. The overall quality of higher education in the United States was abysmally low, and until it improved dramatically, there could be little hope that mathematics, for example, would develop at the research level [45, pp. 91-92]. In sum, Newcomb contended that

[w]e are deficient in the number of men actively devoted to scientific research of the higher types, in public recognition of the labors of those who are so engaged, in the machinery for making the public acquainted with their labors and their wants, and in the pecuniary means for publishing their researches. Each of these deficiencies is, to a certain extent, both a cause and an effect of the others. ... The supply of any one ... would, to a certain extent, remedy all the others; and until one or more are so remedied, it is hopeless to expect any great improvement [45, p. 118].

While Newcomb accurately pinpointed a number of the country's needs in the mid 1870s, he expressed his fundamentally pessimistic view of the future just as a sequence of events was about to take place that would quickly put American science on the kind of course he envisioned. In 1876, the Johns Hopkins University opened in Baltimore as an institution of higher education that emphasized, from its inception, high-level teaching as well as the pursuit and publication of original research by both its faculty and graduate students 11 The idea, imported largely from Prussia, was that teaching loads should be kept low in order to allow time for research, that through graduate-level courses and seminars faculty would prepare students to enter the ranks of the creative researcher, and that this environment would be mutually conducive to the production of new knowledge. Moreover, to allow for the diffusion of that new knowledge, the university underwrote the publication of journals in a variety of fields, among them mathematics, chemistry, philology, and history. These journals, although they highlighted the work of the Hopkins community, also served as publication outlets for the American intellectual community as a whole and, in so doing, helped provide a key element of the infrastructure that Newcomb found so lacking.

Newcomb's essays thus bring into sharp relief the difficulties inherent in the exercise of taking stock of mathematics in the United States. As soon as such a pronouncement is made, circumstances may change in totally unforeseen ways to affect developments - positive or negative - that were previously unimagined. Ideas and whole areas that seem seminal may swiftly wane in importance. Conflicts that appear intractable may ultimately be resolved. For these reasons, reflective evaluations of the state of the discipline provide a unique perspective not only on how mathematicians view their subject at a given point in time but also on the field's historical trajectory.

\footnotetext{
${ }^{1}$ On the place of the Johns Hopkins University in the history of mathematics in the United States, see [50] and [57].
} 


\section{The EMERGENCE OF RESEARCH-LEVEL MATHEMATICS IN AMERICA}

If Simon Newcomb despaired of mathematics in the United States in the 1870s, he was apparently somewhat more sanguine about its prospects at the close of 1893 when he addressed the then New York Mathematical Society at its annual meeting. After all, in the two decades since his commentaries, dramatic changes had taken, and were taking, place in the American educational landscape. The Hopkins experiment had proven successful. Professors there were not only training students at the research level, but they were also beginning to make substantial contributions themselves to the store of knowledge. Moreover, these two functions, as in the Prussian universities, proved mutually reinforcing. Forward-thinking university presidents and faculty members at extant schools like Harvard [8] and Cornell [16] as well as at newly formed institutions such as Clark University 18 and the University of Chicago [51 increasingly embraced the Hopkins model [57]. Relative to mathematics in particular, this, together with the fact that many Americans had studied in Germany in the closing years of the nineteenth century, had resulted in a small but critical mass of mathematicians dedicated to research and to building the infrastructure necessary to nurture and sustain a research community [28], [29]. In fact, in the years since 1876, no fewer than three new periodicals - the American Journal of Mathematics, the Annals of Mathematics, and the Bulletin of the New York Mathematical Society - had been founded to promote mathematical communication in the United States. The success of this last journal, in particular, reflected the growing strength of a professional community of mathematicians defined by its own specialized scientific society. Mathematicians who affected these changes were among those in Newcomb's audience in December of 1893.

Choosing nothing less than "Modern Mathematical Thought" as his topic, Newcomb sought in his lecture to characterize trends in late nineteenth-century mathematics with, as he put it, "a view of pointing out in what direction progress lies, and what is the significance of mathematical investigation at the present day" [47. p. 95]. Underlying this goal was the assumption that his words would not fall on deaf ears, that his American listeners were poised to take mathematics in the direction he indicated. In his view, mathematical "progress has been made by going back to elementary principles, and starting out to survey the whole field from a higher plane than that on which our predecessors stood, rather than by continuing on the lines which they followed" [47 p. 96]. In this way, seemingly disparate concepts and contexts had been united by, for example, the notion of a group and the theory of functions of a complex variable [47, pp. 97-103]. The geometrical application of the algebraic theory of invariants afforded to his mind yet another striking example of this sort of mathematical unification [47, p. 100], as did Felix Klein's analysis of the rotation groups associated with the Platonic solids and the developments in $n$-dimensional and non-Euclidean geometries [47, pp. 102-106]. Moreover, the accompanying abstraction proved liberating. As Newcomb put it, "[w]ith us mathematics is no longer the science of quantity. But even if we consider that the ultimate object of mathematics is relations between quantities, we have reaped a rich reward by the emancipation, for we are enabled by the use of our broader ideas to reach new conclusions as to metric relations" [47, p. 101].

Despite his acknowledgment of the power of late nineteenth-century methods and approaches, Newcomb closed his lecture on a cautionary note. "To guess the future of mathematical science would be a rash attempt," he admitted. "If made it 
might seem that, in view of the extraordinary works of the human intellect which mark our age, the safest course would be to predict great discoveries in this and all other branches of science. ... But it does not follow that our posterity will solve many problems which we have attacked in vain ..." [47] p. 107]. While this may be true enough, Newcomb's vision of the future did not seem to include the possibility that new avenues of research might open up and that new research agendas might be embraced. Less than ten years after Newcomb put forth his views, David Hilbert first published his Grundlagen der Geometrie (1899) and then laid out his twenty-three mathematical problems at the International Congress of Mathematicians in Paris in 1900. In the United States, Eliakim Hastings Moore and his students, Leonard Eugene Dickson, Oswald Veblen, and Robert L. Moore at the University of Chicago, together with Edward V. Huntington at Harvard, responded particularly to Hilbert's call for foundational research and defined what would come to be known as the "American school of postulate theory" [66], perhaps the first geographically extended, thematically oriented, research-level "school" of mathematics to be supported within the context of the emergent American mathematical community [57, pp. 382-387], [52, [7, pp. 15-19].

This later work, like the ideas singled out in Newcomb's characterization of modern mathematical thought, lay unquestionably in pure - in contradistinction to applied-mathematics. Emory McClintock, an actuary at Mutual Life Insurance Company of New York and the president of the Society at the time Newcomb gave his speech, briefly focused in his retiring presidential address on the disparity in the United States between these two aspects of mathematics. Citing the fact that instruction in the colleges and universities tended to the pure rather than to the applied, McClintock thus concluded that "our young mathematician who says to himself that he will make a discovery is most likely to confine his efforts to that in which he has been most thoroughly instructed, and with which he is therefore the most familiar - the pure science" [40, p. 93].

While this may have been, in fact, much more likely, applied mathematics was not absent in the United States. Harvard's Benjamin Peirce, although well known today for his ground-breaking work in 1870 on the theory of algebras [58, [55. pp. 250-261], was better known in his own day for the rigorous curriculum in the mathematics of celestial mechanics that he taught as early as the mid 1840s [57, pp. 17-20], for his very precise calculation of the orbit of the planet Neptune (newly discovered in 1846) as well as of Neptune's perturbations by the planet Uranus, and for his guidance of the applied work of the U. S. Coast Survey as its superintendent from 1867 to 1874. Similarly, George William Hill, the third president of what had in 1894 become the American Mathematical Society, pursued his research in celestial mechanics in the context of his position at the Nautical Almanac Office and lectured on the subject at Columbia University for four years in the closing decade of the nineteenth century [5. p. 117]. When Hill devoted his retiring presidential address in December of 1895 to "Remarks on the Progress of Celestial Mechanics since the Middle of the Century", the story he told was one that took place exclusively abroad and largely at the hands of Henri Poincaré in France and Hugo Gyldén in Sweden [36]. Perhaps he was too modest to mention his own seminal work on the three-body problem [35], [57] pp. 38-39], but Hill did underscore the difficulty of pursuing such lines of research in the United States. "In America," he argued, "we are not well situated for investigations of this character, on account of the meagreness of our libraries. Of no inconsiderable number of 
memoirs and even books, having at least some importance in our subject, there exist no copies in the United States. Hence, should an American be inclined to undertake the task of writing the history of our subject, he must at least perform some of the work abroad" [36, p. 126]. Of course, Hill could equally well have included pursuit of the subject at the research level in the latter analysis.

Although Hill singled out no American contributions to celestial mechanics for mention, Robert S. Woodward, professor of mechanics and later of mechanics and mathematical physics at Columbia, presented things differently in his retiring AMS presidential address four years later. Taking as his topic "The Century's Progress in Applied Mathematics", Woodward focused specifically on analytical mechanics, geodesy, dynamical astronomy, observational astronomy, elasticity, and hydromechanics and gave a general overview of nineteenth-century developments in these areas 80]. To be sure, most of those developments, in his view, were European, but he made a special effort to highlight the work of American researchers wherever possible.

For example, Woodward dated the beginnings of geodesy to the work of AlexisClaude Clairaut in mid eighteenth-century France, interpreted it as recast at the hands of Pierre Simon de Laplace and Adrien-Marie Legendre at the beginning of the nineteenth century, and found it significantly systematized and extended by Wilhelm Friedrich Bessel somewhat later in the century [80, p. 142]. Against this backdrop of distinguished European contributors, however, Woodward prominently placed an American. In Woodward's view, "the general character of the circulation of the atmosphere and the meteorological consequences thereof, have been brought within the domain of mathematical research if they have not yet been wholly reduced to quantitative precision. The pioneer in this work was a fellow-countryman, William Ferrel, (1817-1891), who like [George] Green, came near being lost to science through the obscurity of his early environment" [80, pp. 143-144]. Associated during the last half of his life with both the Nautical Almanac Office and the U. S. Coast Survey, Ferrel drew from the mathematics of Laplace's Mécanique céleste in formulating his innovative, if ultimately insufficient, mathematization of the motions of the atmosphere and of the ocean in relation to the rotation of the earth 2 Woodward, admittedly addressing a partisan audience, held this work in great enough esteem to include mention of it in a thirty-page survey of the history of applied mathematics throughout the whole of the nineteenth century. The research of three other Americans - himself, Hill, and Newcomb - also figured in his account [80, pp. 145, 147, and 151].

Woodward's nationalistic agenda came out even more forcefully at the close of his address. Referring to the "brilliant progress" made in applied mathematics in the nineteenth century, he asked "what part the American Mathematical Society may play in promoting further advances" [80, p. 162]. His answer to that question was clear. The AMS should foster research in applied mathematics, not, as he put it, by "urging the cultivation of pure mathematics less, but rather [by] suggesting the pursuit of applied mathematics more" [80, p. 163]. Woodward's position would be echoed by several of his successors, but despite these counsels, the AMS would come almost exclusively to support pure as opposed to applied mathematics. (On institutional developments in applied mathematics in the United States, however, see below.)

\footnotetext{
${ }^{2}$ On Ferrel's life and work, see [2].
} 
As if to counterbalance Woodward's call for the support of applied mathematics in the United States, Yale mathematician James Pierpont took the podium at the Mathematical Congress held in conjunction with the St. Louis World's Fair in September of 1904 to trace "The History of Mathematics in the Nineteenth Century" 59], while three months later, outgoing AMS president Thomas Fiske used his retiring address to survey "Mathematical Progress in America" 30. Both men treated pure mathematics exclusively. Fiske, in particular, specifically excused himself from any broader scope by citing Woodward's earlier talk. He also recognized Woodward's nationalistic agenda of "includ[ing] a description of the more important advances made by Americans in the field of applied mathematics" [30. p. 238], as he blatantly announced his own in the very title of his lecture. Pierpont was perhaps more subtle, but his aim was transparent. Like Woodward, he sought to situate American contributions within the predominantly European history of nineteenth-century mathematics in an effort to emphasize the success of the newly emergent American mathematical research community.

Pierpont divided pure mathematics into twelve leading areas: complex function theory; the theory of elliptic and hyperelliptic functions and their integrals; automorphic functions; differential equations; group theory; set theory; the theory of real-valued functions; number theory; and projective, differential, non-Euclidean, and other geometries. In almost each of these categories, he singled out American contributors to place side-by-side with the Europeans. In his account of complex function theory, for example, the names of such mathematicians as Karl Weierstraß, Carl Runge, David Hilbert, Henri Poincaré, and Thomas Stieltjes are followed by that of the University of Wisconsin's Edward Burr Van Vleck for his work on the theory of infinite fractions [59, p. 138]. In differential equations, Hill's work on infinite determinants received recognition alongside the research of Lazarus Fuchs and Henri Poincaré [59, p. 141], while relative to the solution of differential equations with boundary conditions, Harvard mathematician Maxime Bôcher figured in a short list that included George Green, Charles Sturm, Joseph Liouville, Bernhard Riemann, Hermann Amandus Schwarz, Carl Neumann, Henri Poincaré, and Émile Picard [59, p. 142]. Real analysis had American representation as well, especially in the researches in the calculus of variations of Chicago's Oskar Bolza [57, pp. 393-396] and Harvard's William Fogg Osgood [59, p. 148]. In the theory of groups, what Pierpont deemed "the second dominant idea of the century" after that of the complex variable [59, p. 142], Americans figured even more prominently. Frank Nelson Cole and George A. Miller worked on determining groups of finite order; E. H. Moore, his student Dickson, and his colleague Heinrich Maschke all contributed to the theory of linear groups during the 1890s at the University of Chicago [59, p. 143], [57, pp. 374-381 and 398-401]. Finally, in spherical geometry, Pierpont named his Yale colleague Percey F. Smith as a major developer together with Gaston Darboux and others, while in the foundations of mathematics, he labeled "Peano, Veronese, Pieri, Padoa, Burali-Forti, and Levi-Civita in Italy, Hilbert in Germany, [E. H.] Moore in America, and Russell in England" as the acknowledged leaders internationally [59. p. 158].

With so much evidence of success both at home and abroad, Pierpont clearly felt justified in closing his speech on a note of unrestrained optimism. "[W]e who stand on the threshold of a new century can look back on an era of unparalleled progress," he told his St. Louis audience. "Looking into the future an equally bright prospect greets our eyes; on all sides fruitful fields of research invite our labor and promise 
easy and rich returns. Surely this is the golden age of mathematics!" [59] p. 159]. Pierpont's "we" here perhaps implied the mathematicians of the United States even more than mathematicians in general. Virtually all of the American strides he had documented had been made during the closing quarter of the nineteenth century as a community of research-level mathematicians coalesced within the universities and around the focal point provided by the American Mathematical Society.

\section{The COnsolidation And GROWTH OF AMERICAN MATHEMATiCs}

With the groundwork for this community solidly laid and with a shared sense of what it meant to be a professional mathematician, Americans in the first four decades of the twentieth century were able to concentrate on maintaining the programs and research agendas already in place and on fostering new initiatives nationwide. During this period, almost thirty institutions, both state-supported and private and located from coast to coast, ran solid doctoral programs in mathematics [9, p. 276], whereas in 1900 only a handful had truly viable graduate programs in the field [57, p. 432] 3

This growth was accompanied by significant changes in and augmentation of the infrastructure for mathematics. Already in 1900, the AMS had launched a new journal, its Transactions, in order to provide for the increasing publication needs of its community of researchers. In 1935, it was joined by the Duke Mathematical Journal, so that by 1940 the United States supported five research-level journals in pure mathematics as well as the American Mathematical Monthly. American mathematicians published their paper-length findings in these outlets at home as well as in periodicals abroad, even if they were only beginning to liberate themselves from the German scene relative to the publication of monographs and advanced textbooks 68. New societies also formed in the first two decades of the century to accommodate what was becoming an increasingly stratified mathematical community 64]. In 1915, after failed negotiations with the AMS to take over the publication of the Monthly, the Mathematical Association of America was created to address the needs of college teachers of mathematics who may or may not have been active researchers. Five years later, the National Council of Teachers of Mathematics formed to serve yet another constituency, mathematics teachers at pre-collegiate levels.

While journals and societies had long been standard features of the mathematical infrastructure, external funding became available for the first time for mathematical research in the aftermath of World War I. Owing to the concerted efforts especially of Princeton's Oswald Veblen, the postgraduate fellowship program of the Rockefeller Foundation and the National Research Council was opened up to mathematicians [25, pp. 72-74]. Another new feature of the American mathematical landscape - and a novel form of external support for mathematical research - the Institute for Advanced Study was endowed in 1930 and opened in Princeton in 1933

\footnotetext{
${ }^{3}$ The twenty-eight American schools G. D. Birkhoff listed in 1938 were: Brown, Bryn Mawr, the California Institute of Technology, the University of California at Berkeley and at Los Angeles, Chicago, Cincinnati, Columbia, Cornell, Duke, Harvard, Hopkins, Illinois, the Institute for Advanced Study, Iowa, Michigan, Minnesota, the Massachusetts Institute of Technology, Notre Dame, Ohio State, Pennsylvania, Princeton, Rice, Stanford, Texas, Virginia, Wisconsin, and Yale. In 1900, the principal Ph.D.-granting institutions in the United States were Yale, Chicago, Hopkins, Clark, Columbia, Harvard, and Cornell. Other schools - like Michigan and Wisconsin-also had small but established programs. See 28. p. 201].
} 
as an institution solely for the unfettered pursuit of new knowledge. It supported a permanent faculty as well as annual "members" who devoted their time exclusively to research [12].

All of these developments took place in a mathematical environment characterized, in historian Loren Butler Feffer's words, by "a privileging of pure over applied mathematics, of research over teaching, and of educating future mathematicians over training others who needed advanced mathematical skills" [25, pp. 66-67]. This ideology comes through quite strongly in the lecture E. B. Van Vleck delivered at the University of Chicago before the departments of mathematics, physics, and chemistry at the school's twenty-fifth anniversary celebration in 1916 [74]. Taking as his topic "Current Tendencies of Mathematical Research", Van Vleck asked "What is the dominant problem or central thought in the research of to-day, if there be one?" [74 p. 2]. He immediately answered that "[i]n the field of applied mathematics probably the 'problem of three bodies' can be picked out as par excellence the present-day problem. Already in the hands of Poincaré this had given a first quickening of the fossilized methods of mathematical astronomy" 74, p. 2]. These two sentences - the first finding only one major problem in all of applied mathematics and the second characterizing mathematical astronomy before Poincaré as practically moribund - were essentially the only two sentences devoted to applied mathematics in the lecture. Van Vleck continued that "[i]n pure mathematics, to which I shall confine my attention, the number of conspicuous problems is legion, but above them all there looms ... the problem of the infinite set. Analysis, geometry, and mechanics alike have been rapidly and increasingly permeated by the point set theory of Georg Cantor, in which the central core is the problem of the infinite set" [74, p. 2]. Pure mathematics, in Van Vleck's view, was vibrant and alive. It teemed with important open problems, the solutions of which promised to unite seemingly disparate subfields. Generalization, but not as he put it "cheap generalization" [74, p. 3], was the watchword, and he approvingly cited the efforts of Hilbert in axiomatization, Lebesgue in formulating his generalized integral, and E. H. Moore in so-called general analysis [67] as examples of how mathematicians should proceed [74, pp. 9-10]. In sum, Van Vleck held modern mathematics to be "characteristic in its generalized sweep, in its creation and use of refined tools and concepts, in its recasting of the problem so as to make it fertile, and lastly in its attainment of success through point set considerations" [74 p. 13]. For him, it "make[s] tremendous advance when questions of theory rather than calculation are involved" for "the combination of sweeping generalization with rigor is astonishing" 74, p. 13].

While it is unclear how the physicists and chemists may have greeted Van Vleck's remarks, he was surely preaching to the converted relative to the mathematicians. After all, long-time department head E. H. Moore had been instrumental in spearheading America's move into pure mathematics, even though he himself had cautioned against allowing mathematics to distance itself too much from the physical sciences in his own retiring presidential address in 1902 [42, [57, pp. 415-418], [25. pp. 70-71]. Moore's student and now Chicago colleague, Dickson had cultivated abstract algebra, and the Chicago department as a whole had trained scores of researchers particularly in algebra, geometry, and the calculus of variations since its inception in 1892. The Chicagoans had played a leadership role in defining the mathematical profession on American shores in terms of pure, abstract, rigorous mathematics, namely, the mathematics they saw as defining the profession abroad 
and especially in Germany 4 Later, in 1916, in his retiring presidential address before the AMS, Ernest W. Brown saw the dominance of purism as potentially harmful in a rapidly changing international political climate.

Brown, like Newcomb and Hill, was a mathematical astronomer and so a researcher more in the applied than in the pure vein. With Europe at war, he recognized the need for hard-core, applied mathematics - numerical methods, curvefitting, the solution of partial differential equations - to address the pressing needs of aviation, meteorology, and other war-related sciences [15, pp. 224-226]. Mathematicians could thus best serve the war effort, especially if the United States were to become involved, by taking on these sorts of very concrete problems. As he put it, "[i]n these wider interests our opportunities for service may come: the readiness and ability that we show in a realization and fulfilment of them will be the chief measure of our success in the past and promise for the future" [15, p. 230]. Yet, how could America's mathematicians be ready for such service given the purist bent of their work?

Brown viewed America's mathematicians as isolationist in their purity in much the same way Europe saw the United States as isolationist in its politics prior to its entry into the war. His argument as to the dangers of mathematical isolationism could almost apply mutatis mutandis in the political context. "While every other product of human thought demands aid from outside," he argued,

modern pure mathematics stands practically alone. Its laws, its logic, what it seeks and what it finds have no necessary relation to externals in the sense of dependence. ... Yet one cannot help asking whether it is for the best interests of the subject that it should continue in this isolation.... One may argue that isolation produces a pure strain, but is it not also true that an occasional crossing of the breed is necessary to prevent the species from running itself out? [15, pp. 216-217].

The war that raged in Europe in 1916 may have focused Brown on the merits of nurturing "the knowledge of the applied mathematician ... as the intermediary between the experimentalist and the pure mathematician" [15, p. 221], but it would not be until World War II that applied mathematics would begin to gain a solid foothold in the United States (see below) 5 American mathematics of the first four decades of the twentieth century remained largely abstract, and the community's élite took great pride between 1920 and 1940 in the advances made in that direction.

Consider, for example, the topics of the retiring presidential addresses during the 1920s. After Johns Hopkins University geometer Frank Morley gave his lighthearted talk on "Pleasant Questions and Wonderful Effects" at the close of 1920 [4], the remainder of the presidents in the twenties got down to business reviewing and

\footnotetext{
${ }^{4}$ This, of course, is not to say that mathematics of a more applied flavor was ignored at Chicago and elsewhere. To take Chicago as just one of any number of possible examples, Forest Moulton taught courses there in mathematical astronomy, and Dickson wrote a textbook on Plane Trigonometry with Practical Applications (1922). Nevertheless, the Chicago program-like the programs at many of the schools listed in the previous note - had a largely purist thrust.

${ }^{5}$ Dickson, Brown's successor as AMS president, who retired just after the close of the war in December 1918, devoted his address to "Mathematics in War Perspective" [22]. As he saw it, the United States had fallen woefully short in mathematical preparedness compared to England, France, and Germany. He exhorted: "Let it not again become possible that thousands of young men shall be so seriously handicapped in their army and navy work by lack of adequate preparation in" mathematics [22, p. 289].
} 
attempting to spur research in a variety of areas. The next three presidents had all been graduate students in E. H. Moore's department at the University of Chicago; their quick succession in the 1920s underscores the success of Moore's educational initiative. Gilbert Ames Bliss, who took over at his alma mater the mantel of the calculus of variations from his adviser Oskar Bolza, spoke in 1922 on "The Reduction of Singularities of Plane Curves by Birational Transformations" [11. Oswald Veblen, by this time one of the animators of the forward-moving program at Princeton, made "Remarks on the Foundations of Geometry" two years later [75. George David Birkhoff, the prime mover of mathematics at Harvard and like Veblen a student of E. H. Moore's, gave "A Mathematical Critique of Some Physical Theories" in 1926 [10].

These former Chicagoans were followed in the presidency by Virgil Snyder of Cornell and Earle Raymond Hedrick, first of the University of Missouri but after 1924 at UCLA. Whereas Bliss, Veblen, and Birkhoff were all home-grown members of the second generation of American research mathematicians, both Snyder and Hedrick had earned their Ph.D.s in Göttingen, Snyder under Felix Klein and Hedrick under Hilbert. Their educational profiles reflect the transition of mathematics at the research level in turn-of-the-twentieth-century America; some would-be mathematicians found programs at home sufficient around 1900, while some still sought their training abroad. By 1930, American mathematical pilgrimages had come almost completely to an end. Regardless of the differences in their initial training, Snyder and Hedrick saw eye-to-eye with Bliss, Veblen, and Birkhoff that research should be highlighted in their presidential addresses. Snyder spoke on "The Problem of the Cubic Variety in $S_{4}$ " in August of 1929 69, and Hedrick treated "Non-analytic Functions of a Complex Variable" in December of 1931 [33]. Bliss's more historically oriented lecture aside, all of these addresses situated American contributions to some extent within the context of general developments in the field.

Perhaps the greatest celebration of the mathematical endeavor in the United States prior to World War II took place, not surprisingly, in 1938 at the semicentennial of the AMS. At that time, not only did then AMS secretary Raymond C. Archibald publish a book-length history of the Society [5], but essays were also solicited on what the Committee on Publications termed "eight representative subjects" [1, p. i] - algebra, the algebraic aspects of the theory of differential equations, harmonic analysis, the calculus of variations, geometry, topology, Dirichlet problems, and hydrodynamical stability - in addition to a survey by G. D. Birkhoff of "Fifty Years of American Mathematics" 9.6 The overall goals of this collection, according to the Committee, were "both to reveal what has been accomplished in America since the founding of the Society, and also to acquaint mathematicians with current problems and research in many fields" [1, p. i]. The agenda was thus overtly nationalistic. The time was ripe officially to chronicle American achievements.

One essay, Norbert Wiener's on "The Historical Background of Harmonic Analysis", placed the work of contemporary mathematicians internationally in the context

\footnotetext{
${ }^{6}$ Given the ongoing debate about the place of applied mathematics in the American mathematical community, the inclusion of John L. Synge's chapter on hydrodynamical stability is noteworthy [71. It shows the AMS's awareness of the importance of applied mathematics and provides evidence that the Committee on Publications sought to bring developments in applied mathematics before a larger cross-section of the AMS readership.
} 
of the field's nineteenth-century developments. For example, in sketching the connections between harmonic analysis and statistical mechanics, Wiener focused on the ergodic hypothesis. In his view, "[i]t is one of the greatest triumphs of recent mathematics in America, or elsewhere, that the correct formulation of the ergodic hypothesis and the proof of the theorem on which it depends have both been found by the elder Birkhoff at Harvard" 78, p. 63]. Wiener's own work - as well as that of Yale's Einar Hille, Princeton's Salomon Bochner, and Brown's Jacob Tamarkin, among the research of earlier Americans like Josiah Willard Gibbs - also figured in Wiener's very internationalized account.

Berkeley department chair Griffith Evans dealt with work related to harmonic analysis as well in his contribution on "Dirichlet Problems" 24], that is, the set of problems surrounding the assignment of arbitrary continuous boundary values to various types of harmonic functions in the plane (cf. 9, pp. 300-301]). Unlike Wiener, however, Evans did not take a historical view of the subject, preferring instead to concentrate on then-recent contributions. Like Wiener, he told an international story in which Americans such as himself and his colleague, Charles B. Morrey, Harvard's Oliver D. Kellogg, and Wiener and Henry Phillips at MIT figured prominently.

A number of the other essays championed particular American schools of research. Columbia's Joseph F. Ritt took a narrow focus in his exposition of algebraic aspects of the theory of differential equations, dealing almost exclusively with his own and results obtained by his students Henry W. Raudenbush and Walter Strodt 63]. Similarly, Tracy Y. Thomas, who had earned his Ph.D. under Veblen at Princeton and served on the faculty at his alma mater before moving to UCLA in 1938, concentrated his remarks about "Recent Trends in Geometry" on work championed by Veblen and carried out largely at Princeton in the 1920s and 1930s on mathematizing relativity theory from a geometrical point of view [73]. Although Thomas kept his treatment at a purely technical level, this topic was, in fact, part of Veblen's larger strategy for "selling" mathematics as "relevant" to new funding sources like the Rockefeller Foundation and the National Research Council [25] pp. $73-75]$.

Edward J. McShane, who had done his research principally under Lawrence M. Graves at the University of Chicago before eventually taking a professorship at the University of Virginia, took a wider view than either Ritt or Thomas in his account of "Recent Developments in the Calculus of Variations" [41. Essentially introduced into the United States by Oskar Bolza at the University of Chicago just after 1900, the calculus of variations became somewhat of an American speciality thanks to the success of the Chicago school. Bolza's student and later successor at Chicago, Bliss trained numerous graduate students, among them Graves and Magnus Hestenes, and helped secure both Graves and William T. Reid for the Chicago faculty. At the same time, G. D. Birkhoff took up work in the calculus of variations, particularly after his move to Harvard in 1912, and supervised the doctoral research of Marston Morse, among others. McShane highlighted the work of this extended American school against the backdrop of European contributions to good effect.

Another area in which American mathematicians can be said to have created well-defined schools in the opening decades of the twentieth century is topology. As a field, topology only emerged toward the end of the nineteenth century and underwent major development thereafter. It was thus a topic that an aspiring mathematician could get in on at the ground level, and the Americans did just that. The 
University of Michigan's Raymond L. Wilder thus felt justified in opening his essay on "The Sphere in Topology" with what he termed "pardonable pride" as "to the part which American mathematicians have played in this development. ... [O]ne may well ponder how much this was due to that great American mathematician, E. H. Moore, by whose students, particularly R. L. Moore and O. Veblen, the actual beginnings of Topology in this country were made" [79, p. 136]. Although Wilder's paper was essentially a topology tutorial intended to introduce the subject "in all its aspects, abstract, set-theoretic, and combinatorial" [79, p. 136], it incorporated in so doing references to theorems and their proofs. Many of these issued from the United States in the work of, to name only a few: Harvard's Hassler Whitney; James W. Alexander, Solomon Lefschetz, Norman Steenrod, and Veblen of what had become the mighty Princeton school of algebraic topology; and R. L. Moore, together with his students Gordon T. Whyburn and Wilder himself, in point set topology [57, pp. 448-450]. Like McShane, Wilder was able to document how thoroughly American work penetrated the growing body of topological knowledge. He reported, however, on a field of rising importance, whereas the calculus of variations was somewhat in decline in the late 1930s as a major area of research.

Finally, in the two essays that had the most overtly nationalistic agendas, Eric Temple Bell tackled algebra [7] and G. D. Birkhoff took on all of mathematics 9]. Both focused exclusively on American achievements. Bell, like Wilder relative to topology, had a particularly triumphal tale to tell. Although James Joseph Sylvester had animated a mathematical school with a fundamentally algebraic thrust at the Johns Hopkins University from 1876 until his departure in 1883 [50], [57, pp. 99-146], [54 pp. 156-235], his nineteenth-century successors there failed to maintain the department's momentum. Like the calculus of variations, algebra found a stronghold at the University of Chicago, where, during the closing decade of the nineteenth century, E. H. Moore focused his research in group theory. His first student, Dickson, defended a dissertation in 1896 on linear groups that became his seminal 1901 book Linear Groups with an Exposition of the Galois Field Theory [21], 56], 7, p. 10]. Dickson went on to train a generation of algebraists at Chicago, among them his successor there, A. Adrian Albert, and Mina Rees. Rees's doctorate, in particular, exemplifies a small but growing segment of America's mathematical research community in the twentieth century-women [29], [32, [27] 7

\footnotetext{
${ }^{7}$ In his address, Bell specifically called attention to the participation of women in the American mathematical community. Referring to the area of modular invariants, he commented that "[i]t is of some interest to note that this field attracted two of the most active American women mathematicians of the period, [Mildred] Sanderson (1889-1914) and [Olive] Hazlett" [7] p. 22]. Like Rees later, both of these women, as well as Mayme Logsdon, worked under Dickson at Chicago. Logsdon even joined her mentor as a colleague on the Chicago faculty in 1921 (but cf. [27]).

Unlike other scientific societies in the late nineteenth and early twentieth centuries, the American Mathematical Society neither enforced special membership criteria for women nor barred them from participation. Graduate programs at Chicago and elsewhere also trained women at the doctoral level in the field. Still, jobs for women in mathematics, as in the other sciences, were almost exclusively limited to the women's colleges or to undergraduate institutions where teaching loads were high, salaries low, and incentives for original research minimal. The universities that trained women thus did not tend to hire them; male faculties were viewed as more prestigious. The Depression only exacerbated the problem, since men, as "breadwinners", had priority in hiring. This situation began to improve only in the 1960s and 1970s, owing in part to the Women's
} 
The theory of algebras was of particular importance among this early twentiethcentury Chicago school's research interests [7. pp. 29-32]. As early as the 1904-1905 academic year, the Scottish mathematician Joseph H. M. Wedderburn brought his Carnegie fellowship there and proved - in hot competition with Dickson - his seminal result that every finite division algebra is, in fact, a field [77, [53. Two years later, he published the fruits of more of the research he had done while at Chicago, namely, his beautifully modern structure theory of algebras [76, [55]. Dickson then moved this theory forward significantly in his 1923 book, Algebras and Their Arithmetics [20], 26] 8 Among the younger generation, Albert focused on the theory of division algebras in the 1930s, and Wedderburn's Princeton doctoral student, Nathan Jacobson, pursued the theory of Lie algebras. This and much other work had put American algebraists at the forefront of the field by 1940 .

Although group theory, and especially the theory of linear groups, was also an early focal point of research at Chicago, classificatory work found broad institutionalization in the United States [7, pp. 8-15]. Frank Nelson Cole, longtime professor at Columbia and secretary of the AMS, had studied under Klein in Leipzig and became a major proponent of the theory of permutation groups. He and his students, especially George A. Miller, embraced a research agenda that involved calculating and enumerating all groups of particular types and orders. Although as Bell recognized even in 1938 "some of the earlier work now seems a trifle old-fashioned" [7] p. 15], it underlay what he termed "one of the most active periods in the history of this country" [7] p. 15]. As is well-known, it revivified spectacularly from the 1950s onward in the form of the massive group effort that resulted in the classification of the finite simple groups [31].

G. D. Birkhoff largely agreed with Bell's assessment of who the major figures in algebra had been over the fifty-year period from 1888 to 1938, but he was more measured in his evaluation of the import of their work in his essay on "Fifty Years of American Mathematics". In his view, we see that there has been a great algebraic advance in the direction of a unified theory of linear associative algebras and their arithmetics, in which we have taken an important part. But while in Europe certain outstanding classical problems have been solvedsuch as the finiteness of complete systems of algebraic invariants and Waring's problem, both in the affirmative sense by Hilbert - we in America have scarcely reached such exalted heights of algebraic achievement. Notwithstanding this fact, we have every right to be very proud of what has already been accomplished among us 9 . p. 292].

On the other hand, to Birkhoff's way of thinking, "the field of pure mathematics called analysis is extraordinarily vast and diversified," and Americans have made "very considerable advances" there [9, 292]. The analyst Birkhoff thus devoted a third of his exposition to analysis, while algebra garnered only a seventh of it 9

As Birkhoff saw it, analysis in America had its roots in the work of four people: his adviser, E. H. Moore, at the University of Chicago; his former teachers and later

Movement and exemplified by the founding of the AWM (American Women in Mathematics) in 1971 to support and encourage women in mathematics.

${ }^{8}$ Its highly influential German translation won the AMS's Cole Prize in 1928.

${ }^{9}$ In his address, Birkhoff also briefly surveyed symbolic logic and axiomatics, geometry, and applied mathematics. 
colleagues, William Fogg Osgood and Maxime Bôcher, at Harvard; and Wisconsin's E. B. Van Vleck, who influenced him through a series of lectures on difference equations [9, pp. 292-296], [57, pp. 204-207]. (The latter three had studied under Klein in Göttingen.) Birkhoff's assessment of American developments in analysis was thus colored by his own educational odyssey as well as by his strong sense of his personal role in those developments.

Birkhoff began with Moore. Although Moore was a multifaceted mathematician, Birkhoff acknowledged that same research in general analysis singled out by Van Vleck in his 1916 address as leading to a school of functional analysis that included Chicago students Graves and Theophil Henry Hildebrant [9, p. 296]. However, Birkhoff found that the work they did tended "to be serviceable rather than particularly exciting" [9, p. 296], while he found the results of John von Neumann as well as his own research with O. D. Kellogg toward "a general program of functional analysis concerning existence theorems ... more effective than the obvious treatment by direct abstraction" [9, p. 297].

If Birkhoff was somewhat equivocal about Moore's legacy in analysis, he was categorical in his appraisal of that of Osgood and Bôcher. Through his seminal Lehrbuch der Funktionentheorie of 1907 [48], Osgood "provided a large part of the present mathematical world with its fundamental training in this field" [9, p. 293]. Osgood's researches particularly influenced Birkhoff's student, Joseph L. Walsh, who, according to the proud adviser, "would probably be regarded today both here and abroad as the American who has above others continued the tradition in the theory of functions of a complex variable begun by Osgood" [9, p. 294]. Moreover, Osgood's early work on ordinary differential equations, together with AMS Colloquium Lectures by Max Mason in 1906 and Bliss in 1909, set the stage for later American work in this area by Ritt and Birkhoff [9, pp. 305-306].

Bôcher's influence on American analysis also reached far. His work on potential theory stimulated the developments Evans outlined in his essay on Dirichlet problems (cf. [9, pp. 300-301]); his results on boundary value problems prompted Birkhoff's interest in that topic. Results of Tamarkin in addition to those of Birkhoff's students Marshall Stone and Rudolph E. Langer continued in this tradition [9, pp. 301-303]. Finally, Van Vleck stimulated especially Birkhoff's research on linear difference equations. This led to what Birkhoff termed the "[r]eally significant" dissertation research in the field by his student Robert D. Carmichael, later of the University of Illinois [9 pp. 303-305].

As for other areas of analysis less directly related to the work of Birkhoff's big four, he singled out the calculus of variations and Fourier series and integrals. Relative to the former, his assessment of its developments on American shores, although much briefer, accorded with McShane's [9, pp. 298-300], while his tour of Fourier series and integrals included prominent mention of Harvard's Dunham Jackson in addition to some of the work Wiener highlighted [9, p. 301]. All in all, Birkhoff found analysis strong in the United States, even if he felt that "we have as yet done very little in partial differential equations and analytic number theory" [9, p. 296].

The semicentennial addresses were thus, by and large, songs in praise of what their authors saw as fifty years of mathematical achievement where before there had been little. Building on the foundation laid between 1876 and 1900, American mathematicians of the first four decades of the twentieth century pursued their research at a level increasingly competitive with that of Europe. At the same time, 
they extended the educational opportunities for mathematical aspirants at home. As the affiliations of the mathematicians featured in the semicentennial addresses indicate, programs at a number of universities, like Harvard, Princeton, and, by the end of the period, MIT and Berkeley, made strong moves toward national leadership. Others, like those at Chicago, Hopkins, and Yale, entered a sort of holding pattern. Still others, at Wisconsin, Illinois, Michigan, and elsewhere, began slow but steady ascents. This period, too, witnessed a strong sense of national pride as well as national boosterism. Ever since Americans started flocking to Europe and particularly to Germany in the 1880s [57, pp. 189-259], the United States had felt - as it was - mathematically inferior to the Continent. By 1940, there was much evidence that that had begun to change, and Americans were quick to herald their accomplishments.

The decade of the 1930s, however, brought a confrontation with that overt nationalism as scores of refugees fled the worsening political situation in Europe and sought asylum in the United States. Leaders of American mathematics such as Veblen and AMS secretary Roland G. D. Richardson labored tirelessly in this Depression era to welcome and to place the displaced scholars, some of whom had been stars of the European mathematical scene. Others, notably Bliss and G. D. Birkhoff, opposed securing jobs for foreigners at the expense of talented Americans [62. Be this as it may, the influx of European mathematicians, coupled with the eventual outbreak of World War II, decidedly shaped the American mathematical scene in the postwar era.

\section{AMERICAN MATHEMATICS IN THE POSTWAR ERA: A CURSORY OVERVIEW}

Whereas the United States had made a fairly dismal showing in mobilizing science during World War I [23], it moved with greater dispatch as the Second World War loomed. Warren Weaver, professor and chair of the mathematics department at the University of Wisconsin and after 1932 head of the Natural Sciences Division of the Rockefeller Foundation, led the mathematics initiative, working closely with the director of the Office of Scientific Research and Development (OSRD), Vannevar Bush. Just months after the U. S. entered the war, the Applied Mathematics Panel (AMP) was formed to coordinate and to mobilize mathematicians within the context of the National Defense Research Committee, a subset of the OSRD [49]. Many mathematicians participated, among them Saunders Mac Lane, Richardson, and Whitney as well as the recent emigrés Richard Courant, Jerzy Neyman, and von Neumann. As even this very partial list makes clear, the expertise in applied mathematics of the emigrés not only contributed fundamentally to the American war effort but also prompted what Peter Lax has termed "the flowering of applied mathematics in America" after the war [39]. In the words of historian Larry Owens, the AMP, owing to the efforts of all who served it, "publicize[d] the role of mathematics in the war and thereby promote[d] its continuing importance afterwards. It accelerated the institutionalization of applied mathematics through its support of groups like Courant's at NYU and Richardson's at Brown, schools that were able to translate wartime associations into postwar support" [49, p. 300] (cf. [43]). The desideratum that Woodward and Brown had emphasized in their lectures before the AMS in the early years of the century was finally supplied, especially after 1950 [19]. Key physical manifestations of this increasing emphasis on more applied research were the extension of industrial research facilities like American Telephone and 
Telegraph's Bell Laboratories to support both mathematical and statistical inquiry and the founding in 1952 of the Society for Industrial and Applied Mathematics.

Although its evolution in the United States differed markedly from that of applied mathematics, statistics, too, benefitted from the presence of the emigrés and from the overall war effort. After a protracted period of professional differentiation from the social scientists and from the social sciences, mathematical statisticians had formed their own society, the Institute of Mathematical Statistics (IMS), in 1935. By 1938, the IMS had also taken over responsibility for the Annals of Mathematical Statistics, a journal that had been founded in 1929 to serve the needs of the more mathematically and theoretically inclined statistical practitioners. Thus, when refugees like Neyman, William Feller, Mark Kac, and Abraham Wald took up positions in the United States at Berkeley, Brown, Cornell, and Columbia, respectively, they were able to participate in a young, but viable, community of mathematical statisticians.

The war also served to strengthen this community's sense of self. Working through both the AMP and the War Production Board's Office of Production Research, mathematical statisticians "trained industrial workers in methods of statistical quality control, and they developed and implemented means of making the equipment used in the war more effective" [37 p. 23]. In particular, through the AMP, Columbia University's Statistical Research Group devised the method now known as sequential sampling for more efficiently determining when enough data have been gathered and so when to stop an experiment. As a result of the war effort, historian Patti Hunter explained, "mathematical statisticians had succeeded in serving other disciplines while advancing their own professional interests. Having defined a niche for themselves, they now had a place from which to continue promoting and strengthening their community" [37, p. 26].

The boundaries of the American mathematical community were thus significantly extended in applied directions over the decades of the 1930s and the 1940s. Nevertheless, the country's purist tradition was also never stronger. This came through quite clearly during the course of a three-day symposium hosted by Princeton's Department of Mathematics in 1946 ostensibly to celebrate the university's bicentennial but surely to celebrate equally the return to peacetime pursuits. Called simply "Problems of Mathematics", the meeting brought together some one-hundred recognized leaders from nine countries in nine areas of pure mathematics - algebra, algebraic and differential geometry, mathematical logic, topology, mathematical probability, analysis and analysis in the large, and "new fields" - to discuss promising future research directions in their respective areas. Although the organizers acknowledged the "wide ramifications" of applied mathematics "into many sciences," time, they said, did not permit them to discuss applied mathematics at the conference. Nevertheless, they "would be concerned with its unifying spirit, pure mathematics" [61, pp. 309-310].

If the definition of future research paths was the pragmatic goal, the organizers also had deeper philosophical ends in mind. "Some schools of mathematics have prided themselves in digging deep wells, others on excavation over a broad area. Progress comes most rapidly by doing both," they asserted.

The increasing tempo of modern research makes these interludes of common concern and assessment come more and more frequently, yet it has been nearly fifty years since much thought has been 
broadly given to a unified viewpoint in mathematics. It has seemed to us that our conference offered a unique opportunity to help mathematics to swing again for a time toward unification 61 . p. 309].

Referring to the vision for mathematics inherent in Hilbert's Paris Congress problems of 1900, the organizers obviously felt that the various areas of pure mathematics had grown too isolated over the course of the first half of the twentieth century. And, while it is not clear whether they tacitly advocated the sort of unification Bourbaki was working toward, they did feel the need for dialogue and consensus regarding the future of their subject.

The conference opened with a discussion of algebra followed by algebraic and differential geometry and mathematical logic. Emil Artin chaired the algebra session, which focused on two main lines of development, "one the generalization of known results with an eye toward increasing their scope and learning more of their inner meaning - this is going on at widely different levels of abstractness - and the other is the continuation along classical lines, represented by Brauer's imposing advance" [61, p. 310]. Brauer had just proven Artin's conjecture about induced characters and had announced his proof at the symposium [13]. As the conference participants realized, this result represented an important "step in the generalization of class-field theory to the non-Abelian case, which is commonly regarded as one of the most difficult and important problems in modern algebra" [61, p. 311]. As Benedict Gross and John Tate pointed out in their 1989 commentary, this result was a harbinger of the so-called Langlands Program 61, p. 335]. In the late 1960s, Robert Langlands saw the linkage between non-Abelian Galois representations and the theory of automorphic forms on reductive groups that had developed largely at the hands of Harish-Chandra [6]. Langlands's conjectures concerning this linkage sparked much research activity by Langlands himself, by Jean-Pierre Serre and Pierre Deligne, and most recently by Michael Harris and Richard Taylor (in 1998) and independently by Guy Henniart (in 1999). The results of the latter three in particular have been described as "a milestone in algebraic number theory" 65. p. 35].

The geometry sessions also produced directions for research and new problems to consider, although perhaps with mixed results. Solomon Lefschetz chaired the discussion of algebraic geometry and structured it by considering "new, deeper problems for the classical algebraic geometry over the field of complex numbers contrasted with new methods for developing algebraic geometry over abstract fields" 61, p. 312]. He specifically posed four problems, only the first of which, to "extend the Riemann-Roch theorem to higher dimensions" 61, p. 312], proved really central to subsequent developments in the field [61, p. 337]. Nevertheless, there was animated discussion about W. V. D. Hodge's then recent work on and conjecture regarding "the rank problem for cycles on the orientable manifold defined by an (irreducible) algebraic variety over the complex numbers" [61, p. 312] and where it might lead. In his modern-day commentary on the session, Herbert Clemens noted that "the authors of the problem list were on target" in their enthusiasm for Hodge theory since "work in [it] motivated by the conjecture has led to some of the deepest mathematics in complex geometry and related fields" [61, p. 338].

The session on differential geometry seemed less forward-thinking. The two discussion leaders, Václav Hlavaty from Prague and Thomas at Princeton, focused 
narrowly on their own personal researches and on problems suggested by them. The ensuing discussion was apparently more interesting, with Bochner detailing some of his new work on "relations between the Ricci curvature of a compact Riemann space and the characteristics of vector fields defined over the space" and Zürich's Heinz Hopf calling "attention to [the then] little-known but very suggestive results of Preissmann (1943) and Cohn-Vossen (1935-1936)" 61, p. 314]. Still, 1989 commentator Robert Ossermann was struck more by what this session omitted than by what it contained; there was no mention reported, for example, of the work of Henri Cartan, Shiing-Shen Chern, or Hermann Weyl [61, p. 339].

The final topic of the first day's deliberations was mathematical logic 10 With Alonzo Church in the chair, Alfred Tarski led a discussion centered on decision problems that sparked lively debates among participants who included Kurt Gödel, Stephen Kleene, and Willard V. Quine. At issue was determining whether or not there is an algorithm for deciding if an object in some arbitrary set has or does not have a particular property [61, p. 343]. Church offered three possible candidates for problems that are not solvable in this sense, namely, "the word problem for groups and the problems of giving a complete set of topological invariants for knots and for closed simplicial manifolds of dimension $n$ " [61 p. 315]. These conjectures did, in fact, generate a significant amount of research over the next two decades, with Church's first and third conjectures being proven true in the 1950s 61, pp. 343344], but mathematical logic had taken on a fundamentally different look by the end of the 1950s. The agendas voiced in 1946 very soon seemed less than central [61, p. 346].

On the conference's second day, the discussion moved to topology, the so-called "new fields", and mathematical probability. Two Americans, Deane Montgomery and Norman Steenrod, together with two Europeans, Hopf and J. H. C. Whitehead, structured the opening session on topology "around two main topics: (a) groups of transformations, [and] (b) classification of homotopy classes of maps, fibre bundles and related questions" [61, p. 317]. Montgomery started off by concentrating on compact transformation groups in general and on Hilbert's fifth problem in particular, namely, "[h]ow far Lie's concept of continuous groups of transformations is approachable ... without the assumption of the differentiability of the functions" [34, p. 12]. This problem had a number of interpretations and spun off numerous related questions. Specifically, Montgomery asked whether "any compact group which acts effectively on a manifold must be a Lie group?" and "[d]oes every periodic transformation of a Euclidean space admit a fixed point?" [61 p. 317]. Although the answer to the first question remains unknown, Pierre Conner and Edwin Floyd addressed the second in 1959 when they provided strong evidence that the answer was in the negative [17] (James Kister modified their example and showed that it was Euclidean space in 1961 [38]), while Montgomery and Leo Zippin together with Andrew Gleason did work in 1952 showing that every locally Euclidean group is a Lie group, thereby solving the fifth problem itself [34, pp. 142-146]. Steenrod and Hopf next focused on homotopy classes and fiber bundles, especially stressing "the need of studying not only the [homology] groups involved but also the homomorphisms connecting them" [61, p. 349]. As William Browder remarked in his commentary,

\footnotetext{
${ }^{10}$ Interest in mathematical logic had been so strong in the United States that the mathematical logicians had founded their own specialized society, the Association of Symbolic Logic, as early as 1934. The Journal of Symbolic Logic started up two years later with Alonzo Church and Cooper H. Langford as editors.
} 
this call "leads quickly (in retrospect) to exact sequences, homological algebra, the Eilenberg-Steenrod axioms for homology, and the general abstract approach" [61] p. 349]. In fact, he continued, there was

enormous development of all the themes represented [in the 1946 topology session], homology and homotopy theories, fiber bundles, group actions, and combinatorial topology, and the spreading of the central parts of these methods (in particular homology and fiber bundle theory) into other areas, until there is hardly an area of mathematics today [1989] in which topology does not play a prominent role, as well as in parts of theoretical physics and molecular biology [61, p. 350].

Relative to topology, as well as to other of the fields surveyed, the symposium organizers' goal of identifying unifying principles in mathematics seems to have been realized.

The session on "new fields" followed, but these "new" fields were apparently limited in the discussion to "classical problems related to application, and of the need and feasibility of revitalizing work in these fields" 61, p. 318]. This should actually come as no surprise, given that John von Neumann served as the session's chair and its discussants were Evans, Synge, Wiener, and Francis Murnaghan, all mathematicians with decidedly applications-oriented interests. The Princeton conference, which its organizers had unabashedly proclaimed as purist, was thus not immune to the growing strength of applied mathematics!

The second day closed in what seemed to be somewhat diffuse deliberations about mathematical probability. A number of noted probabilists and mathematical statisticians participated in the session-among them Harald Cramér, Joseph Doob, William Feller, Harold Hotelling, Mark Kac, Abraham Wald, and Samuel Wilks - but there seemed to be little sense of a shared vision of the field. Hotelling, for example, wondered why statistics was absent from their discussion, while Kac quipped about "the difficulties of further advances in some fields of stochastic processes" [61, p. 321]. "It seems to me," he said, "[the] discussion could be summarized by saying that people were using difference equations to calculate probabilities when they didn't know what probability was, and that now we know what probability is, but can't calculate it" [61, p. 321]. As Doob remarked in his 1989 commentary, the problem in 1946 was that the methods of mathematical probability were still in flux. Kolmogorov had published the seminal text in which he built probability up on a measure-theoretic foundation in 1933. "Unfortunately," as Doob put it, "the significance of his work was not appreciated for years, and some mathematicians sneered that probability should not bury its spice in the bland soup of measure theory, that perhaps probability needed rigor, but surely not rigor mortis" 61, p. 353]. In Doob's view, then, the session on mathematical probability at the Princeton conference was, in some sense, premature.

Analysis took center stage on the symposium's third and final day. In the first session, Marcel Riesz discussed the modern development of potential theory, Antoni Zygmund concentrated on Fourier analysis, and Lars Ahlfors focused on problems associated with the distribution of the values of analytic functions of a complex variable. The second and closing session turned to analysis in the large, the two main tools of which were the calculus of variations and fixed point theory. As the participants recognized, these represented different approaches with different 
strengths. The lengthy "discussion of their properties and contrasts" [61, p. 324] suggested an underlying sense of a split within the field, as did Morse's division of the session into three separate categories followed by the immediate caveat that this was "all for convenience and has nothing to do with essential differences" 61 p. 323]. Karen Uhlenbeck seemed to confirm that a split proved imminent in her 1989 commentary. Today, she said, the subject "has exploded into dynamical systems, differential topology, minimal surface theory, global differential geometry, analysis on Riemannian manifolds, complex geometry and several complex variables, non-linear elliptic and parabolic equations, nonlinear hyperbolic equations and a whole realm of various subjects in mathematical physics and applied mathematics" [61, p. 357]. As was the case with mathematical logic, the practitioners of analysis in the large in 1946 would probably not have recognized their field four decades later.

If "analysis in the large" was perhaps an unnaturally broad rubric in need of further differentiation, the overall message of unification came through strongly throughout the conference. As Saunders Mac Lane remarked at the closing dinner,

In almost all the conferences we ran across the phenomenon of someone else moving in. I think this is a significant aspect of this conference. When you set out to solve problems in mathematics, even in nicely labelled fields, they may well lead you into some other field. To cite some instances: The logicians moved in on the algebraists, the topologists moved in on the differential geometers (and vice versa), and the analysts moved in on the statisticians [61, p. 325].

This sort of intermixing would characterize much of the mathematics of the remainder of the twentieth century (cf. [70]).

The new research highlighted at the Princeton conference and surely the research projected for the future were carried out in a rapidly expanding postwar environment. These decades found mathematicians engaged in their research, but, as G. Bailey Price emphasized, they also

established new journals and edited old ones, revitalized many departments of mathematics and established new graduate programs, conducted summer institutes for high school and college teachers of mathematics, organized and maintained programs of visiting lecturers, established curriculum projects for secondary schools and undergraduate programs, strengthened and expanded their mathematical organizations and created new ones, and developed new organizational arrangements for cooperation on problems of mutual interest [60, p. 379].

In particular, the 1950s and early 1960s witnessed the founding of the National Science Foundation (NSF) (1950), the Sputnik launchings (1957), and the entry of the United States into the space race (1961). All of these events spurred American scientists and mathematicians in record numbers in their research as well as in their commitment to effective, quality education [60, p. 382]. For the first time in history, the federal government appropriated large sums of money for the support of science and its infrastructure. Federal grants, primarily from the NSF, funded mathematical projects from the mammoth classification of the finite simple groups in the 1980s, long under the direction of Daniel Gorenstein at Rutgers University 
31], to the solution of the four-color problem in 1977 by Kenneth Appel and Wolfgang Haken, both then of the University of Illinois at Urbana-Champaign [3], [4], to the proof of Fermat's Last Theorem in 1995 by Princeton's Andrew Wiles [81, [72]. With this sort of support, however, came greater responsibilities. Science policy, that is, politics at the federal level, increasingly became something that scientists had to confront, especially in the 1980s and 1990s. These and many other factors - the computer, new waves of mathematical immigration from the former Soviet Union, China, and elsewhere, the tightening of the federal budget relative to basic research - shaped the American mathematical scene at the end of the twentieth century, but that is a story that only the historian of the late twenty-first century will be in a position to tell.

One thing is certain. During the twenty-five-year period from 1876 to 1900, an American community of research mathematicians emerged where none had been before. This community consolidated and grew over the next fifty years to the point where American mathematicians could stand on their own relative to the Europeans who had always been their standard-bearers. Still, as witnessed both in the semicentennial addresses of 1938 and to a lesser extent at the Princeton conference in 1946, there was very much a sense of an American accomplishment, of national pride and boosterism even at mid-century. By 1988 and the centennial of the AMS, American mathematics had truly come into its own. The speakers at the centennial conference, "Mathematics into the Twenty-First Century", no longer felt compelled to stress American results. The areas they surveyed were the product of an international effort in which they were full partners [14. By the closing decades of the twentieth century, the dream of those early activists like E. H. Moore had been realized: American mathematicians no longer looked to others as standard-bearers; they were among the standard-bearers themselves.

\section{REFERENCES}

[1] American Mathematical Society, Semicentennial Addresses of the American Mathematical Society, New York: American Mathematical Society, 1938, reprint ed., New York: Arno Press, 1980. MR 85m:01103b MR 89i:01138

[2] Anonymous, Biographical Memoir of William Ferrel, in Biographical Memoirs of the National Academy of Sciences, vol. 3, 1895, pp. 265-309.

[3] Kenneth Appel and Wolfgang Haken, Every Planar Map Is Four Colorable. I. Discharging, Illinois Mathematics Journal 21 (1977), 429-490. MR 58:27598c

[4] Kenneth Appel, Wolfgang Haken, and John Koch, Every Planar Map Is Four Colorable. II. Reducibility, Illinois Mathematics Journal 21 (1977), 491-567. MR 58:27598b

[5] Raymond C. Archibald, A Semicentennial History of the American Mathematical Society, 1888-1938, New York: American Mathematical Society, 1938, reprint ed., New York: Arno Press, 1980. MR 85m:01103a

[6] James Arthur, Harmonic Analysis and Group Representations, Notices of the American Mathematical Society 47 (2000), 26-34.

[7] Eric Temple Bell, Fifty Years of Algebra in America, 1888-1938, in Semicentennial Addresses of the American Mathematical Society, New York: American Mathematical Society, 1938, pp. 1-35, reprint ed., New York: Arno Press, 1980. MR 85m:01103b

[8] Garrett Birkhoff, Mathematics at Harvard, 1836-1944, in A Century of Mathematics in America-Part II, ed. Peter L. Duren et al., Providence: American Mathematical Society, 1989, pp. 3-58. MR 91h:01092 
[9] George D. Birkhoff, Fifty Years of American Mathematics, in Semicentennial Addresses of the American Mathematical Society, New York: American Mathematical Society, 1938, pp. 270-315, reprint ed., New York: Arno Press, 1980. MR 85m:01103b

[10] George D. Birkhoff, A Mathematical Critique of Some Physical Theories, Bulletin of the American Mathematical Society 33 (1927), 165-181.

[11] Gilbert Ames Bliss, The Reduction of Singularities of Plane Curves by Birational Transformation, Bulletin of the American Mathematical Society 29 (1923), 161-183.

[12] Armand Borel, The School of Mathematics at the Institute for Advanced Study, in A Century of Mathematics in America-Part III, ed. Peter L. Duren et al., Providence: American Mathematical Society, 1989, pp. 119-148. MR 91k:01016

[13] Richard Brauer, On Artin's L-Series with General Group Characters, Annals of Mathematics 48 (1947), 502-514. MR 8:503g

[14] Felix Browder, ed., Mathematics into the Twentieth Century: 1988 Centennial Symposium, August 8-12, Providence: American Mathematical Society, 1992.

[15] Ernest W. Brown, The Relation of Mathematics to the Natural Sciences, Bulletin of the American Mathematical Society 23 (1917), 213-230.

[16] Gary G. Cochell, The Early History of the Cornell Mathematics Department: A Case Study in the Emergence of the American Mathematical Research Community, Historia Mathematica 25 (1998), 133-153. MR 99e:01032

[17] Pierre Conner and Edwin Floyd, On the Construction of Periodic Maps without Fixed Points, Proceedings of the American Mathematical Society 10 (1959), 354-360. MR 21:3860

[18] Roger Cooke and V. Frederick Rickey, W. E. Story of Hopkins and Clark, in A Century of Mathematics in America-Part III, ed. Peter L. Duren et al., Providence: American Mathematical Society, 1989, pp. 29-76. MR 91h:01026

[19] Amy Dahan Dalmedico, L'Essor des mathématiques appliquées aux États-Unis: L'Impact de la seconde guerre mondiale, Revue d'histoire des mathématiques 2 (1996), 149-213.

[20] Leonard Eugene Dickson, Algebras and Their Arithmetics, Chicago: University of Chicago Press, 1923, (German translation: Algebren und Ihre Zahlentheorie, Zürich and Leipzig: Orell Füssli Verlag, 1927).

[21] Leonard Eugene Dickson, Linear Groups with an Exposition of the Galois Field Theory, Leipzig: B. G. Teubner Verlag, 1901.

[22] Leonard Eugene Dickson, Mathematics in War Perspective, Bulletin of the American Mathematical Society 25 (1919), 289-311.

[23] A. Hunter Dupree, Science in the Federal Government: A History of Policies and Activities, Baltimore: The Johns Hopkins University Press, 1986.

[24] Griffith C. Evans, Dirichlet Problems, in Semicentennial Addresses of the American Mathematical Society, New York: American Mathematical Society, 1938, pp. 185-226, reprint ed., New York: Arno Press, 1980. MR 85m:01103b

[25] Loren Butler Feffer, Mathematical Physics and the Planning of American Mathematics: Ideology and Institutions, Historia Mathematica 24 (1997), 66-85. MR 98f:01042

[26] Della Dumbaugh Fenster, Leonard Eugene Dickson and His Work in the Arithmetics of Algebras, Archive for History of Exact Sciences 52 (1998), 119-159. MR 99e:01020

[27] Della Dumbaugh Fenster, Role Modeling in Mathematics: The Case of Leonard Eugene Dickson, Historia Mathematica 24 (1997), 7-24. MR 98c:01031

[28] Della Dumbaugh Fenster and Karen Hunger Parshall, A Profile of the American Mathematical Research Community: 1891-1906, in The History of Modern Mathematics, ed. Eberhard Knobloch and David E. Rowe, vol. 3, Boston: Academic Press, 1994, pp. 179-227. MR 95i:01009

[29] Della Dumbaugh Fenster and Karen Hunger Parshall, Women in the American Mathematical Research Community: 1891-1906, in The History of Modern Mathematics, ed. Eberhard Knobloch and David E. Rowe, vol. 3, Boston: Academic Press, 1994, pp. 229-261. MR 95i:01010

[30] Thomas Fiske, Mathematical Progress in America, Bulletin of the American Mathematical Society 11 (1905), 238-246.

[31] Daniel Gorenstein, The Classification of the Finite Simple Groups. A Personal Journey: The Early Years, in A Century of Mathematics in America-Part I, ed. Peter L. Duren et al., Providence: American Mathematical Society, 1988, pp. 447-476. MR 90g:01031 
[32] Judy Green and Jeanne LaDuke, Women in the American Mathematical Community: The Pre-1940 Ph.D.s, The Mathematical Intelligencer 9 (1) (1987), 11-23. MR 89f:01096

[33] Earle Raymond Hedrick, Non-Analytic Functions of a Complex Variable, Bulletin of the American Mathematical Society 39 (1933), 75-96.

[34] Felix Browder, ed., Mathematical Developments Arising from Hilbert's Problems: Part I, Providence: American Mathematical Society, 1976. MR 54:7158

[35] George William Hill, On the Part of the Motion of the Lunar Perigee Which Is a Function of the Mean Motions of the Sun and Moon, Acta Mathematica 8 (1886), 1-36 (this work was initially published and distributed privately in 1877).

[36] George William Hill, Remarks on the Progress of Celestial Mechanics since the Middle of the Century, Bulletin of the American Mathematical Society 2 (1896), 125-136.

[37] Patti Wilger Hunter, Drawing the Boundaries: Mathematical Statistics in 20th-Century America, Historia Mathematica 23 (1996), 7-30. MR 96j:01031

[38] James M. Kister, Examples of Periodic Maps on Euclidean Spaces without Fixed Points, Bulletin of the American Mathematical Society 67 (1961), 471-474. MR 24:A783

[39] Peter D. Lax, The Flowering of Applied Mathematics in America, in A Century of Mathematics in America-Part II, ed. Peter L. Duren et al., Providence: American Mathematical Society, 1989, pp. 455-466. MR 90m:01037

[40] Emory McClintock, The Past and Future of the Society, Bulletin of the American Mathematical Society 1 (1895), 85-94.

[41] Edward J. McShane, Recent Developments in the Calculus of Variations, in Semicentennial Addresses of the American Mathematical Society, New York: American Mathematical Society, 1938, pp. 69-97, reprint ed., New York: Arno Press, 1980. MR 85m:01103b

[42] Eliakim Hastings Moore, On the Foundations of Mathematics, Science 17 (1903), 401-416.

[43] Cathleen Morawetz, The Courant Institute of Mathematical Sciences, in A Century of Mathematics in America-Part II, ed. Peter L. Duren et al., Providence: American Mathematical Society, 1988, pp. 303-307. MR 90k:01056

[44] Frank Morley, Pleasant Questions and Wonderful Effects, Bulletin of the American Mathematical Society 27 (1921), 309-312.

[45] Simon Newcomb, Abstract Science in America, 1776-1876, North American Review 122 (1876), 88-123.

[46] Simon Newcomb, Exact Sciences in America, North American Review 119 (1874), 286-308.

[47] Simon Newcomb, Modern Mathematical Thought, Bulletin of the New York Mathematical Society 3 (1894), 95-107.

[48] William Fogg Osgood, Lehrbuch der Funktionentheorie, Leipzig: B. G. Teubner, 1907.

[49] Larry Owens, Mathematicians at War: Warren Weaver and the Applied Mathematics Panel, 1942-1945, in The History of Modern Mathematics, ed. David E. Rowe and John McCleary, 2 vols., Boston: Academic Press, Inc., 1989, pp. 2:287-305. CMP 90:07

[50] Karen Hunger Parshall, America's First School of Mathematical Research: James Joseph Sylvester at the Johns Hopkins University 1876-1883, Archive for History of Exact Sciences 38 (1988), 153-196. MR 89f:01039

[51] Karen Hunger Parshall, E. H. Moore and the Founding of a Mathematical Community in America: 1892-1902, Annals of Science 41 (1984), 313-333, reprinted in A Century of Mathematics in America - Part II, ed. Peter L. Duren et al., Providence: American Mathematical Society, 1989, pp. 155-175. MR 86h:01049 MR 90k:01011

[52] Karen Hunger Parshall, Entering the International Arena: E. H. Moore, the University of Chicago, and Hilbert's Grundlagen der Geometrie, in Proceedings of the Fourth International Galdeano Symposium: June 1999, ed. Elena Ausejo and Mariano Hormigón, to appear.

[53] Karen Hunger Parshall, In Search of the Finite Division Algebra Theorem and Beyond: Joseph H. M. Wedderburn, Leonard E. Dickson, and Oswald Veblen, Archives internationales d'Histoires des Sciences 33 (1983), 274-299. MR 86c:01045

[54] Karen Hunger Parshall, James Joseph Sylvester: Life and Work in Letters, Oxford: Clarendon Press, 1998. MR 99k:01072

[55] Karen Hunger Parshall, Joseph H. M. Wedderburn and the Structure Theory of Algebras, Archive for History of Exact Sciences 32 (1985), 223-349. MR 86h:01050

[56] Karen Hunger Parshall, A Study in Group Theory: Leonard Eugene Dickson's Linear Groups, The Mathematical Intelligencer (1991) (1), 7-11. MR 92b:01046 
[57] Karen Hunger Parshall and David E. Rowe, The Emergence of the American Mathematical Research Community, 1876-1900: J. J. Sylvester, Felix Klein, and E. H. Moore, HMATH, vol. 8, Providence: American Mathematical Society and London: London Mathematical Society, 1994. MR 95j:01032

[58] Benjamin Peirce, Linear Associative Algebra with Notes and Addenda by C. S. Peirce, Son of the Author, American Journal of Mathematics 4 (1881), 97-229 (this was originally published and distributed privately in 1870).

[59] James Pierpont, The History of Mathematics in the Nineteenth Century, Bulletin of the American Mathematical Society 11 (1904), 136-159.

[60] G. Bailey Price, The Mathematical Scene, 1940-1965, in A Century of Mathematics in America-Part I, ed. Peter L. Duren et al., Providence: American Mathematical Society, 1988, pp. 379-404. MR 90g:01036

[61] Princeton University Bicentennial Conference, Problems in Mathematics (Followed by Commentaries), in A Century of Mathematics in America-Part II, ed. Peter L. Duren et al., Providence: American Mathematical Society, 1989, pp. 309-359.

[62] Nathan Reingold, Refugee Mathematicians in the United States of America, 1933-1941: Reception and Reaction, Annals of Science 38 (1981), 313-338, reprinted in A Century of Mathematics in America-Part II, ed. Peter L. Duren, et al., Providence: American Mathematical Society, 1989, pp. 175-200. MR 82f:01190

[63] Joseph F. Ritt, Algebraic Aspects of the Theory of Differential Equations, in Semicentennial Addresses of the American Mathematical Society, New York: American Mathematical Society, 1938, pp. 35-55, reprint ed., New York: Arno Press, 1980. MR 85m:01103b

[64] David L. Roberts, Albert Harry Wheeler (1873-1950): A Case Study in the Stratification of American Mathematical Activity, Historia Mathematica 23 (1996), 269-287. MR 97i:01040

[65] Jonathan Rogawski, The Nonabelian Reciprocity Law for Local Fields, Notices of the American Mathematical Society 47 (2000), 35-41.

[66] Michael Scanlon, Who Were the American Postulate Theorists?, Journal of Symbolic Logic 56 (1991), 981-1002.

[67] Reinhard Siegmund-Schultze, Eliakim Hastings Moore's General Analysis, Archive for History of Exact Sciences 52 (1998), 51-89. MR 2000b:01024

[68] Reinhard Siegmund-Schultze, The Emancipation of Mathematical Research Publishing in the United States from German Dominance (1878-1945), Historia Mathematica 24 (1997), 135-166. MR 98e:01022

[69] Virgil Snyder, The Problem of the Cubic Variety in $S_{4}$, Bulletin of the American Mathematical Society 35 (1929), 607-642.

[70] Marshall Stone, The Future of Mathematics, Journal of the Mathematical Society of Japan 9 (1957), 493-507. MR 20:813

[71] John L. Synge, Hydrodynamical Stability, in Semicentennial Addresses of the American Mathematical Society, New York: American Mathematical Society, 1938, pp. 227-269, reprint ed., New York: Arno Press, 1980. MR 85m:01103b

[72] Richard Taylor and Andrew Wiles, Ring-theoretic Properties of Certain Hecke Algebras, Annals of Mathematics 141 (1995), 553-572. MR 96d:11072

[73] Tracy Y. Thomas, Recent Trends in Geometry, in Semicentennial Addresses of the American Mathematical Society, New York: American Mathematical Society, 1938, pp. 98-135, reprint ed., New York: Arno Press, 1980. MR 85m:01103b

[74] Edward Burr Van Vleck, Current Tendencies of Mathematical Research, Bulletin of the American Mathematical Society 23 (1916), 1-13.

[75] Oswald Veblen, Remarks on the Foundations of Geometry, Bulletin of the American Mathematical Society 31 (1925), 121-141.

[76] Joseph H. M. Wedderburn, On Hypercomplex Numbers, Proceedings of the London Mathematical Society 6 (1907), $77-118$

[77] Joseph H. M. Wedderburn, A Theorem on Finite Algebras, Transactions of the American Mathematical Society 6 (1905), 349-352.

[78] Norbert Wiener, The Historical Background of Harmonic Analysis, in Semicentennial Addresses of the American Mathematical Society, New York: American Mathematical Society, 1938, pp. 56-68, reprint ed., New York: Arno Press, 1980. MR 85m:01103b 
[79] Raymond L. Wilder, The Sphere in Topology, in Semicentennial Addresses of the American Mathematical Society, New York: American Mathematical Society, 1938, pp. 136-184, reprint ed., New York: Arno Press, 1980. MR 85m:01103b

[80] Robert S. Woodward, The Century's Progress in Applied Mathematics, Bulletin of the American Mathematical Society 6 (1900), 133-163.

[81] Andrew Wiles, Modular Elliptic Curves and Fermat's Last Theorem, Annals of Mathematics 141 (1995), 443-551. MR 96d:11071

Departments of History and Mathematics, University of Virginia, Kerchof Hall, Charlottesville, VA 22903-3199

E-mail address: khp3k@virginia.edu 